\title{
Reducing formaldehyde emission of urea formaldehyde-bonded particleboard by addition of amines as formaldehyde scavenger
}

\begin{abstract}
Particleboard is one of the building materials that contribute to the emittance of formaldehyde in enclosed area. In order to reduce the formaldehyde emission from particleboard, amines were added into the urea formaldehyde (UF) resin as formaldehyde scavenger. The amines used were methylamine, ethylamine and propylamine. $0.5,0.7$ and $1 \%$ of each type of amine were added into UF resin and the mixtures were used to produce particleboard from rubberwood particles. The properties of the UF resin after addition of amines such as gelation time, viscosity, $\mathrm{pH}$, free formaldehyde content and thermal stability were evaluated. The physical, mechanical properties and formaldehyde emission of the produced boards were also assessed. The results revealed that fully cured amine-containing UF resin possesses higher thermal stability compared to control UF resin. Amine-containing UF resin also had longer gelation time due to higher $\mathrm{pH}$ value. Nevertheless, both physical and mechanical properties of the resultant particleboard were negatively affected. Particleboard made from aminecontaining UF resin had higher thickness swelling and water absorption. In addition, lower bending strength and internal bonding strength were also recorded. Insufficient pressing time for fully cured of resin might be the reason for such phenomenon. Particleboard with $\mathrm{F}^{* * *}$ emission level $(0.5 \leq \mathrm{x} \leq 1.5 \mathrm{mg} / \mathrm{L})$ as specified in Japanese Industrial Standard (JIS) or European's E0 class equivalent were achieved when ethylamine and propylamine were added, regardless of dosage used. This study showed the feasibility of using amines as formaldehyde scavenger. However, optimisation of processing parameters is needed to enhance the physicomechanical properties of the particleboard.
\end{abstract}

Keyword: Particleboard; Formaldehyde catcher; Methylamine; Ethylamine; Propylamine 